\title{
Revista de Arqueologia Pública
}

FREDEL, Karla Maria. Arqueologia de Gênero nas cidades de Pelotas - RS - Brasil e Habana Vieja - Habana - Cuba / século XIX. Erechim, RS: Habilis Press, 2015, $214 \mathrm{p}$.

Juan Manuel Cano Sanchiz ${ }^{1}$

Arqueologia de Gênero nas cidades de Pelotas - RS - Brasil e Habana Vieja Habana - Cuba / século XIX es la publicación de la Tesis Doctoral homónima de Karla Ma Fredel, defendida en el Instituto de Filosofia e Ciências Humanas de la Universidade Estadual de Campinas (UNICAMP), en octubre de 2012. La tesis se desarrolló bajo la orientación del profesor Dr. Pedro Paulo A. Funari (Laboratório de Arqueologia Pública, NEPAM/UNICAMP) y la co-orientación de los profesores Dra. Lourdes Domínguez (Oficina del Historiador de La Habana; Academia de la Historia de Cuba) y Dr. Lúcio Menezes Ferreira (Laboratório Multidisciplinar de Pesquisa Arqueológica, UFPel). Todos ellos han contribuido a esta nueva obra con sendos prólogo (Domínguez), prefacio (Funari) y presentación (Ferreira).

Este libro contribuye al desarrollo de la incipiente Arqueología de Género a través de un análisis comparativo de dos muestras de estudio pertenecientes a contextos diferentes, aunque conectados por el consumo común de loza doméstica de tipo colonial: la residencia Francisco Antunes Maciel, en la ciudad de Pelotas (Río Grande del Sur, Brasil), y la denominada casa Prat Puig, en Habana Vieja (provincia de La Habana, Cuba). La autora se propone, además, reflexionar sobre dos aspectos diferentes de la sociedad decimonónica pelotense y habanera: el género y la clase, abordados desde los binomios femenino-masculino y señor-esclavo.

Desarrollar simultáneamente dos estudios de caso, en países con realidades emparentadas (sociedades aristócratas, patriarcales y esclavistas) pero diferentes (colonias portuguesa y española), y con un doble foco, implica una notable dificultad y la necesidad de redoblar esfuerzos, o de desdoblarse como investigador. Desde este punto de vista, el trabajo de Fredel, valiente y poco común, merece ser destacado. Sobre todo porque no se limita a interpretar los casos de estudio dentro de sus respectivos contextos nacionales, sino

${ }^{1}$ Facultad de Ciencias y Letras de la UNESP en Assis (SP, Brasil), proyecto Memória Ferroviária. Becario de Post-Doctorado FAPESP: grant \#2014/12473-3, São Paulo Research Foundation. Las opiniones, hipótesis y conclusiones o recomendaciones expresadas en este material son responsabilidad del autor y no necesariamente reflejan la visión de la FAPESP. Contato: laciudadcritica@gmail.com 


\section{Revista de Arqueologia Pública}

que los conecta con el exterior para reflexionar sobre la formación de las sociedades modernas en la órbita del mundo capitalista.

El marco de dichas reflexiones es la Arqueología de Género, que busca ofrecer narrativas diferentes sobre la historia de las mujeres y las mujeres en la Historia a partir, principalmente, de la cultura material asociada al mundo femenino. En palabras de Fredel, su trabajo persigue "o resgate da voz feminina, pouco presente das narrativas históricas" (FREDEL, 2015: 49) por diversos motivos (culturales, políticos, religiosos), incluso porque, según ideas de Michelle Perrot (2007), nuestro propio lenguaje contribuye, con sus plurales masculinos, a silenciar la voz de las mujeres en las fuentes escritas.

Por otro lado, Fredel halla sus bases teóricas en la Arqueología postprocesual; es decir, contextual. Ello implica atender a la importancia del contexto en un doble plano. De un lado, el contexto pasado en el que acontecieron los problemas estudiados. De otro, el contexto presente del investigador, que ciertamente condiciona la representación del pasado a partir de nuestras preguntas y de nuestra particular y subjetiva manera de percibir la realidad. En este libro encontramos a una mujer del presente (Karla Fredel) que reflexiona sobre la vida de otras mujeres del pasado (anónimas). Según mi propia percepción, el contexto de Fredel (nuestro hoy en el estado de São Paulo) se caracteriza, en relación con el tema abordado, por una presencia creciente del feminismo activista en el ambiente universitario (mayor o menor en función de qué facultades) y por la consolidación de palabras como paridad, equidad o género en el vocabulario político. Pero Fredel se sirve de una metodología arqueológica impecable para producir una lectura no intencionada del pasado, una lectura que, desde la subjetividad que caracteriza a las Humanidades, puede considerarse imparcial. En otras palabras, los resultados de Fredel son valiosos para el avance del conocimiento porque se basan en un proceso de investigación riguroso y académico que, lejos de caer en la propaganda, reivindica con argumentos consistentes el papel femenino en la Historia. En este sentido, Fredel matiza que el hecho de que el espacio característico de la mujer en los contextos estudiados fuese el hogar no implica una devaluación de sus funciones. La mujer desempeñó entonces una serie de tareas muy importantes para el equilibrio y buena marcha familiar (en diferentes ámbitos), si bien es cierto que ello aconteció generalmente en una sociedad de marcado carácter machista y paternalista.

Todas estas ideas son planteadas desde un enfoque fundamentalmente cultural. Siguiendo a autoras como Andréa Gonçalves (2006) o Michelle Perrot (2007), Fredel entiende que la categoría género releva a un segundo plano la cuestión biológica, caracterizando las diferencias entre sexos como una construcción cultural. En efecto, este 


\section{Revista de Arqueologia Pública}

no es un libro de Antropología Física, sino de Arqueología. Con todo, en nuestra opinión el cuerpo humano también participa en la modelación del comportamiento y los hábitos. El objeto compresa, por ejemplo, pertenece al ámbito de la cultura material femenina debido a una necesidad fisiológica exclusiva de las mujeres dentro de un determinado rango de edad, aunque su uso se limite a ciertos contextos. Estamos de acuerdo en que buena parte de las diferencias existentes entre hombres y mujeres pueden explicarse desde los sistemas culturales y sociales en los que estos se insertan, pero el sexo (macho/hembra, en un sentido darwinista) también determina.

En otro orden de cosas, este libro refleja una realidad creciente en el campo de la Arqueología: la progresiva compartimentación de la disciplina en diferentes especialidades temáticas y cronológicas. La Arqueología de Género puede entenderse como un enfoque temático de aplicación diacrónica. Con todo, Fredel se centra en un periodo concreto (el siglo XIX) para analizar cómo un objeto determinado (la loza doméstica) puede reflejar ciertas mudanzas sociales de escala global.

Más específicamente, los problemas estudiados por Fredel, magistralmente contextualizados, se enmarcan en un periodo de cambio definido por la formación de la sociedad capitalista y del mercado global. El libro es interesante por mostrar cómo el consumo de los mismos materiales de importación pudo generar rasgos comunes en espacios diferentes y distantes. Esto se manifiesta, de manera evidente, en los gustos, rastreables en las formas y esquemas decorativos de las piezas compradas, pero también en cuestiones más complejas, como las relaciones sociales. A pesar de lo dicho, y como advierte la autora, los contextos de cada ambiente de consumo, y las diferencias existentes entre los propios consumidores, añaden también algunas especificidades.

Entre estas últimas, cabe destacar el particular proceso de industrialización brasileño, sobre el que este libro incide tangencialmente. Siguiendo ideas de Nelson Sodré (1998), Fredel defiende que en Brasil no existía un esquema de industrialización capaz de absorber la transición del trabajo servil al asalariado, lo que produjo un brusco hiato de dramáticas consecuencias para la población. En tales circunstancias, la comercialización de la producción agropecuaria (más específicamente, del charque) en Río Grande del Sur favoreció una serie de contactos con el exterior sobre la base de la exportación-importación. Fueron los productores y comerciantes de charque quienes, enriquecidos por las exportaciones y convertidos en elite pelotense, comenzaron a importar artículos de lujo europeos y norteamericanos (entre ellos la loza doméstica estudiada por la autora, pero también vestidos, muebles y hasta materiales constructivos) como elemento de distinción. En una sociedad que se va haciendo más cosmopolita, los rasgos exógenos (presentes en 


\section{Revista de Arqueologia Pública}

los objetos de consumo, en la decoración arquitectónica e incluso en la educación de la propia prole) son leídos en clave de estatus y se vuelven hegemónicos en el ámbito comercial.

Fredel defiende que la penetración de estos productos fue más rápida que los valores que justificaban su uso, lo cual abre la puerta a un horizonte de interpretación que, más allá de la utilidad práctica de los objetos, conecta con su valor simbólico. Por otro lado, la dispersión global de la loza doméstica, que en el siglo XIX tuvo uno de sus principales centros de producción en Inglaterra, manifiesta la formación del sistema de producción y consumo de masa. O sea, la aparición de la sociedad de consumo.

La autora recuerda, basándose en Charles Orser (2000), que una parte muy importante de los artefactos vinculados a contextos arqueológicos de los siglos XIX y XX (y XXI) son resultado de un proceso de fabricación industrial. Es decir, objetos que a menudo son distribuidos y consumidos por personas diferentes a las que los producen. El artefacto puede configurarse así como un vínculo o elemento de conexión entre el receptor y el emisor de la cultura material, a veces ligados a sistemas socio-culturales muy diferentes e incluso separados espacialmente por miles de kilómetros. A este respecto, uno de los resultados más reveladores del trabajo de Fredel es que sus dos estudios de caso presentan las mismas tipologías a pesar de estar separados físicamente por casi $7000 \mathrm{~km}$ en línea recta.

No obstante, Fredel logró identificar dos marcas de fabricantes brasileños entre un total de cinco reconocidas (el resto, tres, inglesas). El dato es sesgado, pero no deja de llamar la atención que en el caso brasileño la producción nacional también tuvo un peso importante en los ajuares domésticos decimonónicos. La cuestión no es baladí, pues nos obliga a revisar algunas hipótesis y a matizar la posible dependencia del exterior y su repercusión (¿o es consecuencia?) en una industrialización débil y tardía. Por otro lado, no debe olvidarse que los productores brasileños optaron por reproducir las formas europeas, marginando así la tradición local o pre-colonial, apenas presente en las aisladas comunidades indígenas.

Desde el punto de vista metodológico, Fredel divide los materiales estudiados (previamente catalogados por los respectivos equipos arqueológicos que intervinieron en las viviendas seleccionadas como estudios de caso) entre objetos usados por hombres y mujeres, de un lado, y por señores y criados, del otro. La autora defiende que los artefactos de cocina se vinculan a la mujer, mientras que los de consumo de alimentos y bebidas son comunes a ambos sexos. Las diferencias más marcadas están en la esfera de la higiene personal. Se echa en falta, en este capítulo, una argumentación más desarrollada que 


\section{Revista de Arqueologia Pública}

justifique este sistema de clasificación por sexos, que a veces resulta poco consistente porque no se explican cuáles son los criterios adoptados. Faltan, además, los contextos arqueológicos específicos de las piezas estudiadas (¿en qué estancia fue encontrado cada artefacto y a qué estructuras y objetos estaba asociado?), que pierden así parte de su valor como fuente de información.

De hecho, esta publicación adolece, de manera general, de una mayor integración de la cultura material en el discurso. Los estudios arqueológicos de Fredel, tanto de las piezas de loza recuperadas en Pelotas y Habana Vieja como de las casas donde estas fueron encontradas, tienen una débil presencia en el libro, reduciéndose a una serie de anexos que ocupan las últimas páginas. Hay así un cierto desfase entre la propuesta de investigación y los resultados presentados, que, aun siendo de gran interés, derivan fundamentalmente de las reflexiones de la autora sobre el tema a partir de un estudio exhaustivo de la bibliografía disponible. Es decir, las conclusiones de Fredel se alejan un tanto de sus estudios de caso, que plantean varios interrogantes que no son resueltos en este volumen. Leído esto en positivo, este libro abre nuevas líneas de investigación y trabajo.

Existe, por otro lado, un desequilibrio en el tratamiento de los problemas tratados (tensiones femenino-masculino y señor-esclavo), con una clara priorización del primero (género) sobre el segundo (estatus). No se contempla, por ejemplo, la cultura material asociada a la mujer esclava, ni se aportan datos sustanciales sobre la vida cotidiana del servicio femenino. La mujer que protagoniza el libro de Fredel es burguesa.

Otro aspecto que podría servir para completar esta obra es la incorporación de referencias a paralelos que ayuden a comprender hasta qué punto lo sucedido en Pelotas y Habana Vieja sigue un determinado patrón (¿copia o modelo?) o constituye alguna singularidad. Debe ser advertido, en conexión con el párrafo anterior, que los dos estudios de caso presentados en este libro se refieren a casas destacadas en sus respectivos ámbitos urbanos. Es decir, viviendas que fueron ocupadas por unidades domésticas pertenecientes a las elites pelotense y habanera. Por tanto, es presumible que algunas de las conclusiones sobre diferencias de género alcanzadas a partir del estudio de la cultura material no tengan validez para otros estratos sociales.

Finalmente, se detectan otros problemas menores que, en caso de una eventual reimpresión o reedición, podrían corregirse, como los errores gramaticales y ortográficos presentes en las citas literales en español.

Más allá de estas pequeñas objeciones, que tal vez podrían mejorar un libro que ya es bueno, esta monografía supone una excelente puesta al día de las corrientes teóricas y 


\section{Revista de Arqueologia Pública}

la bibliografía sobre el tema Arqueología de Género. Este volumen tiene un fuerte sesgo teórico, y es cierto que se echa de menos una mayor contribución de la evidencia física de los casos de estudio. Pero ello puede justificarse, en buena medida, por el carácter innovador del trabajo planteado por Fredel, que tanto en Brasil como en Cuba puede considerarse pionero. Era necesario, así, el peso que la autora otorga al estudio crítico del estado de la cuestión, siendo de destacar que consigue definir un marco epistemológico propio para la Arqueología de Género a partir de una mirada amplia y global a la teoría arqueológica y a su desarrollo.

Al mismo tiempo, este libro cumple su objetivo de favorecer una mejor comprensión de los procesos de formación de la sociedad contemporánea y del papel de la mujer en la misma. Puede considerarse, por tanto, una obra de lectura recomendada para todos los interesados en el estudio del pasado reciente desde la Arqueología Histórica (o desde la Arqueología de la Industrialización, que no solo se preocupa por la producción de bienes, sino también por su distribución y consumo), especialmente para quienes deseen saber más sobre la organización de las unidades domésticas decimonónicas en Brasil y Cuba, la caracterización de sus espacios físicos y su asimilación del nuevo orden mundial traído por la industrialización capitalista.

\section{Referencias bibliográficas}

FREDEL, Karla Maria. Arqueologia de Gênero nas cidades de Pelotas - RS - Brasil e Habana Vieja - Habana - Cuba / século XIX. Erechim: Habilis Press, 2015.

GONÇALVES, Andréa Lisly. História e Gênero. São Paulo: Autêntica Editora, 2006.

ORSER Jr., Charles. Introducción a la Arqueología Histórica. Buenos Aires: Instituto Nacional de Antropología y Pensamiento Latinoamericano (INAPL), 2000.

PERROT, Michelle. Minha história das mulheres. São Paulo: Editora Contexto, 2007.

SODRÉ, Nelson Werneck. Panorama do Segundo Império. Río de Janeiro: Editora Graphia, 1998. 